\title{
Mechanical and Thermal Properties of R-High Density Polyethylene Composites Reinforced with Wheat Straw Particleboard Dust and Basalt Fiber
}

\author{
Min Yu, ${ }^{1}$ Haiyan Mao, ${ }^{2}$ Runzhou Huang $\mathbb{D}^{2},{ }^{2}$ Zhenghao Ge, ${ }^{1}$ Pujian Tian, ${ }^{1}$ \\ Lixin Sun, ${ }^{1}$ Qinglin Wu $\mathbb{D}^{3},{ }^{3}$ and Kai Sun ${ }^{1}$ \\ ${ }^{1}$ College of Mechanical \& Electrical Engineering, Shanxi University of Science \& Technology, Xi'an 710021, China \\ ${ }^{2}$ College of Materials Science and Engineering, Nanjing Forestry University, Nanjing 210037, China \\ ${ }^{3}$ School of Renewable Natural Resources, Louisiana State University Agricultural Center, Baton Rouge, LA 70803, USA
}

Correspondence should be addressed to Runzhou Huang; runzhouhuang@gmail.com

Received 1 September 2017; Revised 30 November 2017; Accepted 12 December 2017; Published 25 March 2018

Academic Editor: Chaoqun Zhang

Copyright (C) 2018 Min Yu et al. This is an open access article distributed under the Creative Commons Attribution License, which permits unrestricted use, distribution, and reproduction in any medium, provided the original work is properly cited.

\begin{abstract}
The effect of individual and combined particleboard dust (PB dust) and basalt fibers (BFs) on mechanical and thermal expansion performance of the filled virgin and recycled high density polyethylene (HDPE) composites was studied. It was shown that the use of $\mathrm{PB}$ dust had a positive effect on improving mechanical properties and on reducing linear coefficient of thermal expansion (LCTE) values of filled composites, because the adhesive of the particle board held the wheat straw fibers into bundles, which made PB dust have a certain aspect ratio and high strength. Compared with the commonly used commercial WPC products, the flexural strength of PB dust/VHDPE, PB dust/RHDPE, and PB dust/VHDPE/RHDEPE at 40 wt $\%$ loading level increased by $79.9 \%, 41.5 \%$, and $53.9 \%$, respectively. When $40 \mathrm{wt} \% \mathrm{~PB}$ dust was added, the crystallization degree of the composites based on three matrixes decreased to $72.5 \%, 45.7 \%$, and $64.1 \%$, respectively. The use of PB dust can help lower the composite costs and increase its recyclability. Mechanical properties and LCTE values of composites with combined BF and PB dust fillers varied with PB dust and $\mathrm{BF}$ ratio at a given total filler loading level. As the BF portion of the PB dust/BF fillers increased, the LCTE values decreased markedly, which was suggested to be able to achieve a desirable dimensional stability for composites. The process provides a useful route to further recycling of agricultural wastes.
\end{abstract}

\section{Introduction}

Recycling of waste plastics and agricultural residues is an effective solution to the sustainable development in the world and has already become a common practice in industry. Substituting virgin plastic composites with recycled plastic composites is proved to be a superior alternative in most environmental aspects and has achieved the highest environmental benefits [1]. Wood plastic composites (WPCs), which consist of thermoplastics and wood fibers, have become a successful commercial building material with a significant increase over the past decades due to their excellent mechanical properties especially when the low density and price are taken into account [2-4]. In recent years, due to the shortage of raw material, WPCs enterprises and research institutions spared no effort to develop substitute biofillers. Previous studies showed that using crop residues such as rice straw, sugar cane, flax, hemp, jute, or tea residues to replace wood fibers improved notably mechanical and thermal properties of WPCs [5-7]. Wu et al. [8] prepared cotton stalk bark (CSB) filled polypropylene and characterized their morphology, mechanical, and thermal properties. The flexural properties and tensile modulus of cotton stalk bark plastic composites were increased with the increasing concentration of CSB. The tensile strengths exhibited a negative correlation with the CSB content, which reached $32.9 \mathrm{Mpa}$ when the CSB added was $30 \%$. Recently, Cholake et al. [9] investigated the effect of waste macadamia sell on enhancing mechanical properties 
of WPC panel. It was shown that the addition of macadamia shell increased the comprehensive modulus $548 \mathrm{MPa}$ for $75 \%$ macadamia shell WPC panel, and thermal property also indicated that the WPC panel has good flame retardant property compared to $100 \%$ plastic panel. However, limited information can be found on industrialized WPCs products from agricultural residues recycling, despite that they were much cheaper than wood. One of the lethal weaknesses is that they are very fluffy and very easily to be moldy, leading to high storage and transport cost in unit weight [10].

It is noteworthy that annually there are plenty of oriented strandboard (OSB) and plywood discarded in European and American and particle board (PB) and medium density fiberboard (MDF) abandoned in Asia [11, 12]. Utilization of these materials in manufacturing of WPCs can not only reduce production costs but also remove the problem of accumulating and discarding wood industry waste. Such postindustrial wooden products are available in huge quantities, quite consistent in moisture, and well-documented origin, which make it possible to be a consistent alternative source to wood fibers [13]. In a previous study, MDF/HDF based WPC showed significantly higher mechanical strength behaviors than standard WPC, which showed that using MDF dust in manufacturing WPC panel had more added worth [14-17]. The advantages of straw particleboard are its rigidity and strength, built-in insulation, and low cost $[18,19]$. Since wheat straw particleboards are not as hard as OSB, they can be easily crushed into particle or powder, which may be used as raw material as natural fiber for WPC. In addition, recycling wheat straw particle board is a meaningful contribution for further recycling of agricultural wastes.

Although individual biofibers can contribute some desirable properties as reinforcement fillers, the mechanical and thermal properties of WPCs can be represented by the hybridization with inorganic fillers $[20,21]$. Previous studies showed that hybridization of wheat straw reinforced recycled PP composites with different inorganic fillers such as heavy calcium carbonate, silicon dioxide, and fly ash improved notably their water absorption and thermal expansion properties. However, the flexural modulus and flexural strength were both reduced when reinforced with three kinds of inorganic fillers, respectively [22]. As a cost-effective and high-strength material for use in composites, basalt fibers (BFs) are gaining a great attention as an alternative to the use of glass fibers in polymer composites [23]. Also, an effective way to enhance the performance of WPCs while minimizing cost and agricultural residues would greatly improve the economic attractiveness of WPCs. Huang et al. [24] showed that incorporating BFs into the HDPE-Talc composites substantially enhanced the thermal expansion property, flexural, tensile, and dynamic modulus without causing a significant decrease in the tensile and impact strength of the composites. The combined filler system with BFs and Talc could offer a balance between cost and performance for WPCs. In this regard, this paper aims at evaluating the effect of individual $\mathrm{PB}$ dust and hybrid fillers (PB dust and BFs) filled virgin and recycled high density polyethylene (HDPE) composites.

\section{Materials Processing and Experiment Methods}

2.1. Raw Materials and Experimental Design. Raw materials for the study included wheat straw particleboard dust (PB dust), basalt fiber (BF), virgin high density polyethylene (VHDPE), recycled high density polyethylene (RHDPE), maleic anhydride grafted polyethylene (MAPE), and lubricant. PB dust was from Dare Technology Co., Ltd., Zhenjiang, China. Basalt fibers were from Anjie Polymer Material Co., Haining, China. VHDPE was grade AD60 with an MFI at $190^{\circ} \mathrm{C}$ and $2.16 \mathrm{~kg}$ weight of $0.7 \mathrm{~g} / 10 \mathrm{~min}$ and a density of $0.96 \mathrm{~g} / \mathrm{cm}^{3}$ (ExxonMobil Chemical Co., Houston, TX, USA). MAPE was grade Epolene TM G2608 with an MFI at $190^{\circ} \mathrm{C}$ and $2.16 \mathrm{~kg}$ weight of $6 \sim 10 \mathrm{~g} / 10 \mathrm{~min}, \mathrm{Mw}$ of $65,000 \mathrm{~g} / \mathrm{mol}$, and acid number of $8 \mathrm{mgKOH} / \mathrm{g}$ from Eastman Chemical Co. (Kingsport, TN, USA). Lubricant was grade TPW 306 from Struktol Co. (Stow, OH, USA).

Experiment design included two factorial experiments. The first experiment was to investigate the effect of individual filler consisting of twelve blends covering one filler (PB dust) and four loading rates (10, 20, 30, and $40 \mathrm{wt} \%$ of total composite weight for $\mathrm{PB}$ dust pallets filler reinforced VHDPE, RHDPE, and VHDPE/RHDPE, resp.). The VHDPE/RHDPE ratio is $1: 1$. The second experiment was designed to study the effect of combined polymer and combined fillers system (VHDPE/RHDPE/basalt fibers/PB dust pallets), consisting of six blends covering one filler weight contents (50 wt\%) and three basalt fibers/PB dust ratios $(2: 1,1: 1$, and $1: 2)$. The VHDPE, RHDPE, and VHDPE/RHDPE were used as a control.

2.2. Sample Preparation. Melt compounding was performed using a Leistritz Micro-27 corotating parallel twin-screw extruder (Leistritz Corporation, Allendale, NJ, USA) with a screw speed of $60 \mathrm{rpm}$. The temperature profile of barrels ranged from 150 to $175^{\circ} \mathrm{C}$. The extrudates were air-cooled and then pelletized into granules. The granules were injectionmolded into standard mechanical test specimens using a Battenfeld Plus 35 injection molding machine (Battenfeld, $\mathrm{NJ})$. The injection temperatures were 190 and $180^{\circ} \mathrm{C}$ for HDPE-PB dust composites and neat HDPE, respectively. All specimens were then conditioned for $72 \mathrm{~h}$ at a temperature of $23 \pm 2^{\circ} \mathrm{C}$ and a relative humidity of $50 \pm 5 \%$ for later characterization.

\subsection{Characterization}

(1) Mechanical Properties. Flexural tests of samples were carried out according to ASTM D790-03, using a CMT6104 SANS Mechanical Testing Machine (Tesla Industrial systems Co., Guangdong, China). Notched Izod impact strengths were measured with XJJ-5 Impact Tester (Jinjian Testing Instrument Co., Chengde, China) according to the ASTM D 256-05. Four samples of each group were tested.

(2) Thermal Expansion Performance. Thermal expansion samples were machined with a miniature table saw along the long direction of samples with a dimension of 43.5 (length) $\times 12.7$ (width) $\times 5.4$ (thickness) $\mathrm{mm}$. The linear 
coefficients of thermal expansion (LCTE) value of each specimen were measured parallel to the long direction over a temperature range from 20 to $-13^{\circ} \mathrm{C}$ and -13 to $60^{\circ} \mathrm{C}$. They were conditioned at $60^{\circ} \mathrm{C}$ in an oven and $-13^{\circ} \mathrm{C}$ in a freezer from their initial equilibrium temperature of $25^{\circ} \mathrm{C}$ prior to size measurements with a Mitutoyo digimatic indicator of $\pm 0.01 \mathrm{~mm}$ accuracy (Mitutoyo Co., Kanagawa, Japan). Five specimens were used for each group. The LCTE for each sample was calculated based on size changes before and after conditioning. The heating and cooling rates were kept constant at $5^{\circ} \mathrm{C} / \mathrm{min}$. The LCTE $\left(\alpha \mathrm{L}, 1 /{ }^{\circ} \mathrm{C}\right)$ was calculated as

$$
\alpha_{L}=\frac{1}{L} \frac{d L}{d T},
$$

where $L$ is the linear dimension of the test sample and $d L / d T$ is the rate of change in the linear dimension per unit temperature.

(3) Crystallization Behaviors. The crystallization behaviors of HDPE in the blends and composites were measured using a differential scanning calorimeter (DSC Q100, TA Instruments, New Castle, DE). Samples of 4-5 mg were placed in aluminium capsules, heated from $40^{\circ} \mathrm{C}$ to $260^{\circ} \mathrm{C}$ at $10^{\circ} \mathrm{C} / \mathrm{min}$, and then melt annealed for $5 \mathrm{~min}$ to eliminate the heat history before being cooled down at $10^{\circ} \mathrm{C} / \mathrm{min}$. The crystallinity levels corresponding to the crystallization of HDPE in blends were normalized to the mass unit of specimens.

2.4. Statistical Data Analysis. Duncan's multiple range tests for pairwise comparisons were used to test the effect of various treatments on measured properties using Statistical Analysis Software SPSS 22. Statistical ranking at the 5\% significance level was provided among the treatments for each property.

\section{Results and Discussion}

3.1. Morphology. Morphology of impact fractured surfaces of composites with $\mathrm{PB}$ dust is shown in Figure 1. Most PB dust appeared to be well dispersed in the VHDPE matrix, indicating that the $\mathrm{PB}$ dust was compounded well with VHDPE matrix (Figures 1(a), 1(b), and 1(c)). Agglomeration of PB dust was observed when PB dust content reached $40 \%$ (Figure 1(d)). In Figures 1(e) and 1(f), more fiber pullouts and increased gaps between two phases were observed compared to these shown in Figure 1(d). These features suggest that VHDPE/RHDPE and RHDPE matrix has a weaker interfacial bonding between wood filler and the matrix. Thus, further surface modification should be studied in the future, especially for the matrix which contained recycled plastic, which could help improve PB dust/polymer interfacial adhesion and play an important role in determining the efficiency of stress transferred from plastic matrix to the reinforcing fibers.

\subsection{Mechanical Properties}

3.2.1. Flexural Property. Flexural properties of PB dust/HDPE composites with $\mathrm{PB}$ dust content from 0 to $40 \mathrm{wt} \%$ were shown in Figure 2(a). Compared with the mechanical properties of commonly used commercial WPC products $\left(\right.$ GeoDeck $^{\mathrm{TM}}$, Report number ESR-1369, manufactured by Green Bay Decking, LLC, WI, US), the flexural strength of PB dust/VHDPE, PB dust/RHDPE, and PB dust/VHDPE/ RHDEPE at $40 \mathrm{wt} \%$ loading level increased by $79.9 \%, 41.5 \%$, and $53.9 \%$, respectively, and modulus improved by $2 \sim 3 \%$. The better flexural properties might be because the adhesive of the particle board held the wheat straw fibers into bundles as it can be seen from Figure 1(b), which made PB dust have a certain aspect ratio and high strength. Therefore, adding PB dust improved the stress transfer efficiency and enhanced the composite stiffness. Flexural modulus of the composite exhibited an increasing trend with increasing $\mathrm{PB}$ dust loading levels. With every $10 \mathrm{wt} \%$ rise of PB dust content, HDPE, RHDPE, and VHDPE/RHDPE based composite showed an average increase of $85 \%, 48 \%$, and $72 \%$, respectively. For HDPE, RHDPE, and VHDPE/RHDPE systems, the modulus, respectively, increased to $2.58 \mathrm{GPa}, 2.22 \mathrm{GPa}$, and $2.55 \mathrm{GPa}$ at the $40 \mathrm{wt} \% \mathrm{~PB}$ dust loading level. It can be inferred that flexural modulus of composite is affected by its component. The interfacial interaction existed between fiber and matrix by addition of $\mathrm{PB}$ dust to plastic matrix, which could make the transmission from matrix to stiff $\mathrm{PB}$ dust and consequently results in increasing the modulus of the composite. The flexural strength increased significantly from 0 to $30 \% \mathrm{~PB}$ dust content but decreased slightly at the $40 \%$ PB dust content level. The increasing PB dust content increased the possibility of stress concentration caused by fiber aggregation, which became the failure point of composite and resulted in lower strength (Figure 1(d)).

3.2.2. Tensile Strength. Tensile properties of PB dust/HDPE composite with different $\mathrm{PB}$ dust loading levels are plotted in Figure 2(b). Tensile modulus of the composite exhibited an increasing trend with increasing $\mathrm{PB}$ dust content in composites. For the neat virgin HDPE, recycled HDPE, and virgin and recycled HDPE, tensile modulus was $1.17 \mathrm{GPa}, 0.71 \mathrm{GPa}$, and $0.96 \mathrm{GPa}$. When $\mathrm{PB}$ dust content was $40 \mathrm{wt} \%$, composites in three kinds of system showed a notable increase to 3.23 GPa, 2.7 GPa, and $3.07 \mathrm{GPa}$, respectively. It can be seen that $\mathrm{PB}$ dust suggested a positive effect on tensile modulus, which might be due to the strength and stiffness of PB dust. For tensile strength, a decreased trend with increasing $\mathrm{PB}$ dust content in composite was observed. When composites were loaded with $40 \mathrm{wt} \%$ PB dust, tensile strength of VHDPE, RHDPE, and VHDPE/RHDPE based composite decreased to 18.14 MPa, $11.48 \mathrm{MPa}$, and $12.06 \mathrm{MPa}$ from the neat VHDPE, RHDPE, and VHDPE/RHDPE of 22.36 MPa, $16.56 \mathrm{MPa}$, and 19.42 MPa, respectively. The constant reduction of tensile strength illuminated that MAPE did not work as a coupling agent leading to the interface adhesion between PB dust and matrix was very weak. The force of tensile will not be transported from matrix to filler effectively.

3.2.3. Impact Strength. The impact strength constantly decreased by increasing PB dust loading level among all three systems. This showed that the MAPE could not improve the interface adhesion between fibers and polymer, which 


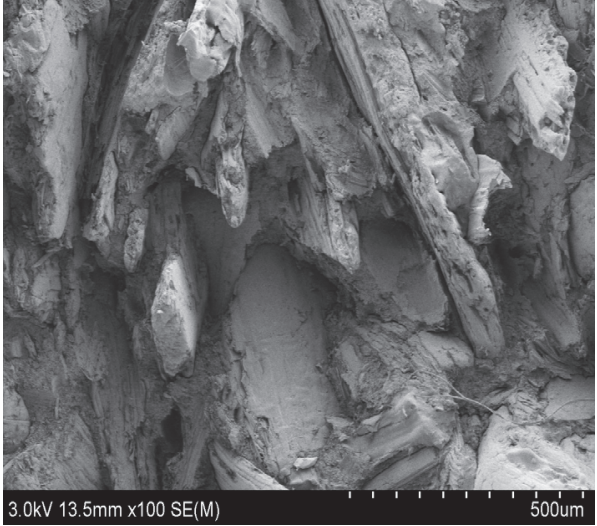

(a)

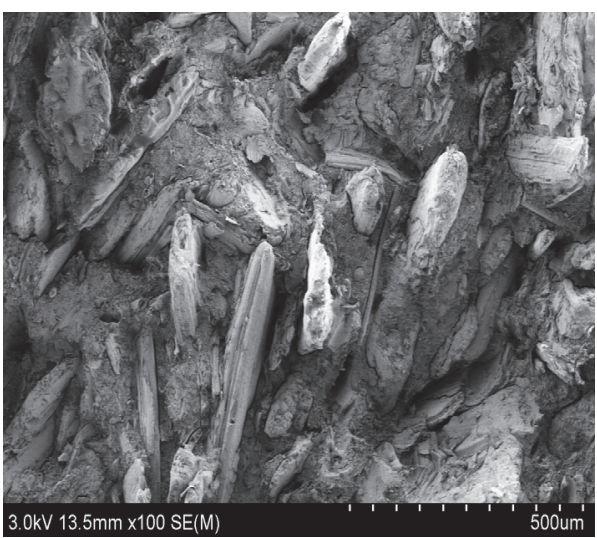

(c)

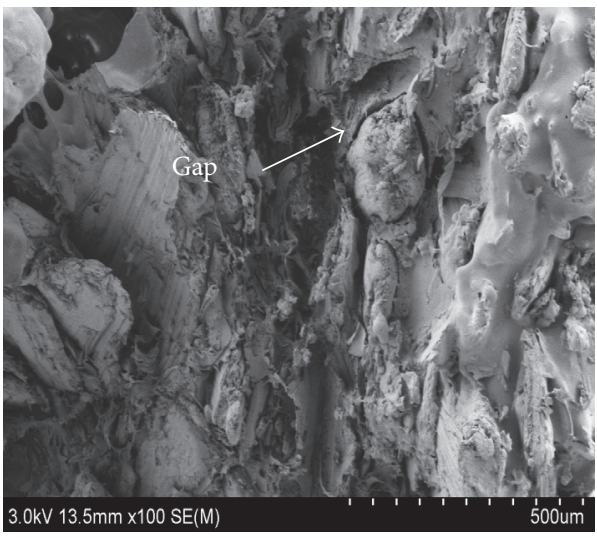

(e)

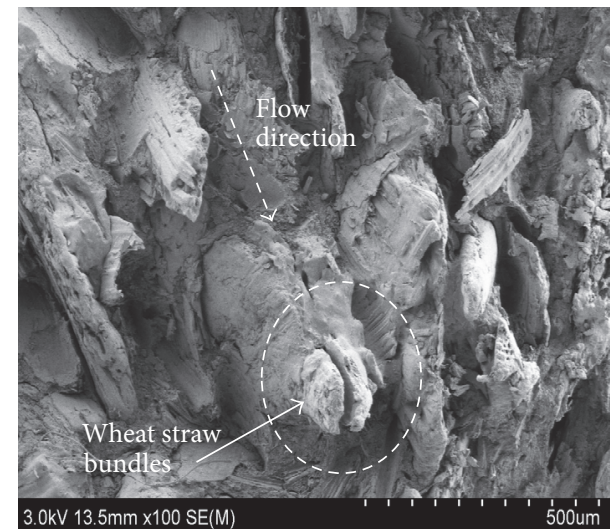

(b)

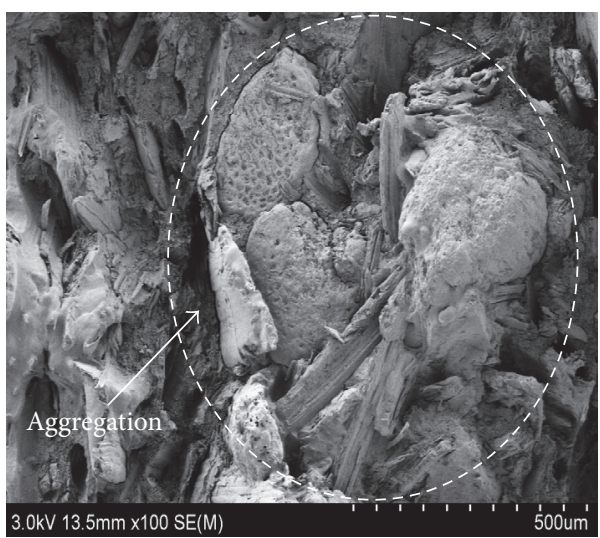

(d)

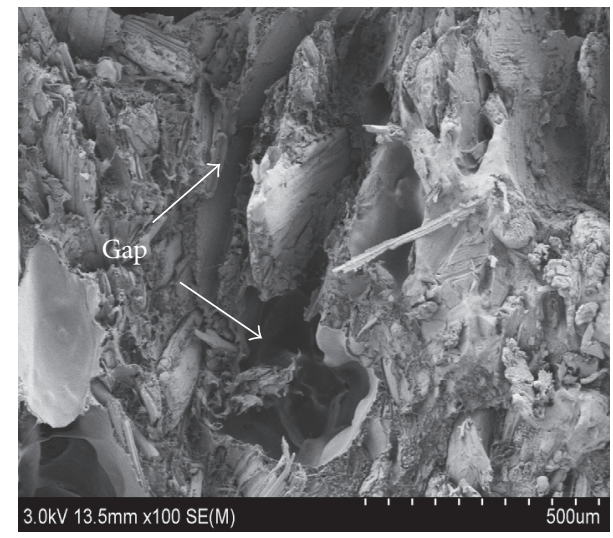

(f)

Figure 1: Morphology of fractured surfaces of WPCs: (a) VHDPE system with 10\% PB dust, (b) 20\% PB dust, (c) 30\% PB dust, (d) 40\% PB dust, (e) VHDPE/RHDPE system with 40\% PB dust, and (f) RHDPE system with 40\% PB dust.

contributed to an assumption that PB dust might be wrapped in adhesive so that there was few hydroxyl groups on the surface, and consequently it was difficult for MAPE to have graft reaction. On the other hand, the addition of stiffness PB dust reduced the toughness of the composite.

3.3. Thermal Expansion Properties. In the process of actual use, WPCs are often subjected to more complex service conditions and wider-ranging working temperatures, which made thermal expansion properties as important as mechanical properties become a crucial engineering performance indicator. A lower LCTE value is one of the most desired properties for WPCs used in outdoor application in order to improve their thermal stability and optimize thermomechanical properties. Table 1 showed measured LCTE values as a function of PB dust content for PB dust filled HDPE polymer. Among three temperature ranges, the first heating cycle $\left(20\right.$ to $60^{\circ} \mathrm{C}$ ) had the largest LCTE, and the second 


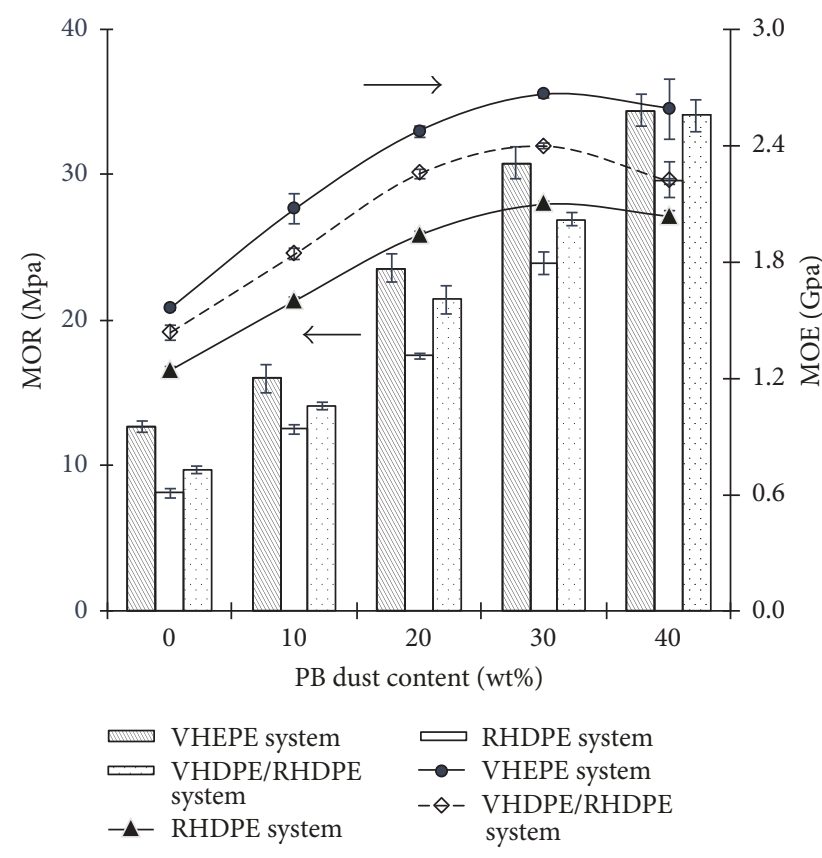

(a)

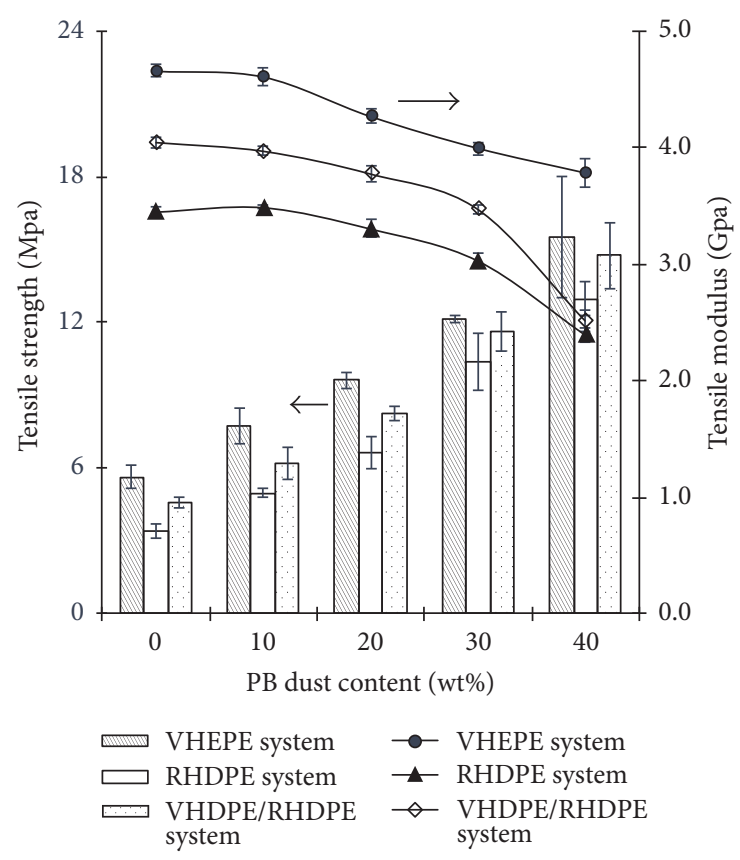

(b)

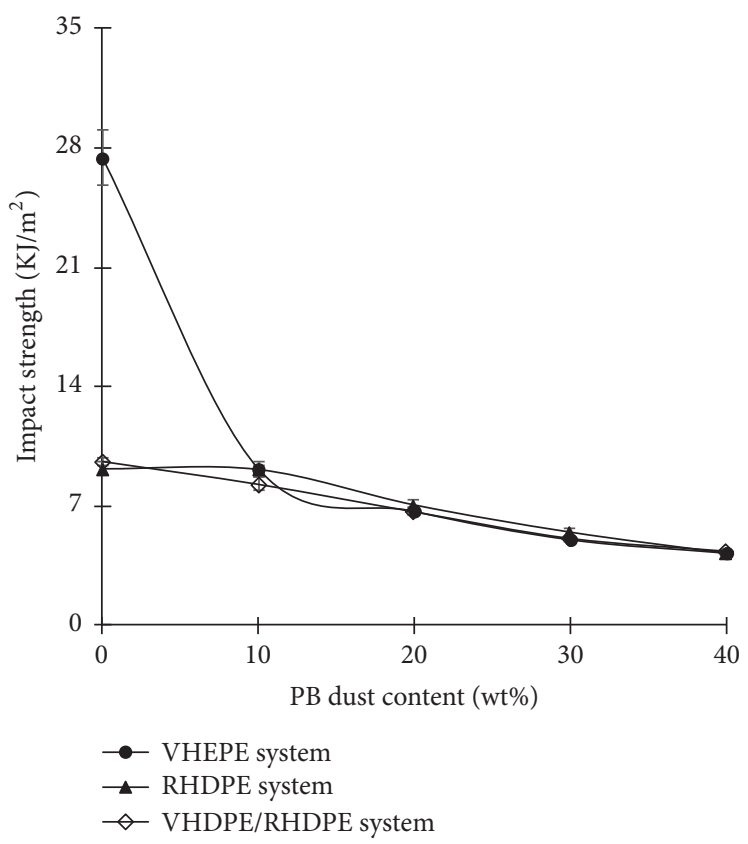

(c)

FIGURE 2: Mechanical properties of PB dust/HDPE composite: (a) flexural properties, (b) tensile properties, and (c) impact properties.

heating cycle ( -30 to $20^{\circ} \mathrm{C}$ ) had the smallest LCTE, which suggested that the thermal expansion behavior of composite was related to the thermal history built into the samples. As implied from the test results reported in Table 1, LCTE decreased with increased PB dust content among three plastic systems. Introducing $10 \mathrm{wt} \% \mathrm{~PB}$ dust in matrix, LCTE values among three plastic systems were observed to decrease by 10 to $15 \%$. With $20 \mathrm{wt} \%$ PB dust loading, the LCTE showed a moderate decrease. The LCTE reduction rate increased greatly with the use of PB dust after the $30 \mathrm{wt} \%$ filling level.
Statistical ranking shows a significant effect of $40 \mathrm{wt} \% \mathrm{~PB}$ dust content on measured LCTE values among all systems, which indicated that the introduction of $\mathrm{PB}$ dust presented positive influences on LCTE of virgin and recycled HDPE, especially at higher loading level.

The LCTE showed an obvious decrease with respect to neat plastic. The LCTE reductions for the temperature ranges of 20 to 60,60 to -30 , and -30 to 20 are $49.2,47.4$, and $38.3 \%$, respectively, for HDPE systems, and 27.5, 27.9, and $23.6 \%$ for the RHDPE system. The corresponding values are, 
TABLE 1: Effect of PB dust content on thermal expansion coefficient of PB dust filled composites.

\begin{tabular}{|c|c|c|c|c|}
\hline \multirow{2}{*}{ System } & \multirow{2}{*}{$\begin{array}{c}\text { Filler content }^{\mathrm{a}} \\
(\mathrm{wt} \%)\end{array}$} & \multicolumn{3}{|c|}{ Linear coefficient of thermal expansion $\left(10^{-6} /{ }^{\circ} \mathrm{C}\right)$} \\
\hline & & 20 to $60^{\circ} \mathrm{C}^{\mathrm{bc}}$ & 60 to $-30^{\circ} \mathrm{C}$ & -30 to $20^{\circ} \mathrm{C}$ \\
\hline \multirow{5}{*}{ VHDPE } & 0 & $177.53(5.36)^{\mathrm{i}}$ & $168.40(3.28)^{\mathrm{i}}$ & $138.48(1.35)^{\mathrm{i}}$ \\
\hline & 10 & $147.67(3.24)^{\mathrm{gh}}$ & $146.50(3.35)^{\mathrm{g}}$ & $129.64(3.34)^{\mathrm{g}}$ \\
\hline & 20 & $143.73(12.27)^{\mathrm{fg}}$ & $136.07(3.29)^{\mathrm{f}}$ & $122.88(3.39)^{\mathrm{f}}$ \\
\hline & 30 & $98.85(1.04)^{\mathrm{b}}$ & $97.80(4.43)^{\mathrm{b}}$ & $88.49(3.10)^{\mathrm{a}}$ \\
\hline & 40 & $90.10(5.69)^{\mathrm{a}}$ & $88.57(6.15)^{\mathrm{a}}$ & $85.41(0.42)^{\mathrm{a}}$ \\
\hline \multirow{5}{*}{ RHDPE } & 0 & $151.17(4.91)^{\mathrm{gh}}$ & $146.40(0.80)^{\mathrm{g}}$ & $124.40(1.14)^{\mathrm{f}}$ \\
\hline & 10 & $136.47(2.87)^{\mathrm{ef}}$ & $136.77(0.58)^{\mathrm{f}}$ & $119.3(6.92)^{\mathrm{ef}}$ \\
\hline & 20 & $133.03(6.85)^{\mathrm{e}}$ & $131.63(1.77)^{\mathrm{ef}}$ & $113.60(3.01)^{\mathrm{d}}$ \\
\hline & 30 & $117.20(3.99)^{\mathrm{d}}$ & $116.93(6.07)^{\mathrm{d}}$ & $100.04(1.50)^{c}$ \\
\hline & 40 & $109.60(2.63)^{\mathrm{cd}}$ & $105.53(2.20)^{\mathrm{c}}$ & $95.01(0.66)^{\mathrm{b}}$ \\
\hline \multirow{5}{*}{ VHDPE/RHDPE } & 0 & $155.67(4.54)^{\mathrm{h}}$ & $154.70(7.32)^{\mathrm{h}}$ & $129.47(1.78)^{\mathrm{g}}$ \\
\hline & 10 & $134.90(4.70)^{\mathrm{e}}$ & $134.10(7.86)^{\mathrm{ef}}$ & $116.30(3.03)^{\mathrm{de}}$ \\
\hline & 20 & $128.67(0.57)^{\mathrm{e}}$ & $127.90(5.31)^{\mathrm{e}}$ & $102.59(4.61)^{c}$ \\
\hline & 30 & $108.30(1.50)^{\mathrm{c}}$ & $108.27(1.27)^{\mathrm{c}}$ & $89.27(0.94)^{\mathrm{a}}$ \\
\hline & 40 & $103.93(1.36)^{b c}$ & $101.97(0.81)^{b c}$ & $86.15(0.74)^{\mathrm{a}}$ \\
\hline
\end{tabular}

${ }^{a}$ The content of each filler was based on the total composite weight. ${ }^{b}$ Mean values with the same lowercased letters for each property are not significantly different at the $5 \%$ significance level. ${ }^{c}$ Numbers in the parenthesis are standard deviation based on five specimens. $d, e, f, g$, h, and i represent data statistics ranking in Duncan's multiple range tests.

respectively, 33.2, 34.1, and 33.5\% for the VHDPE/RHDPE system. It was because of a small LCTE of PB dust and the reduction of plastic content in composites $[25,26]$. Noticeably, though among three plastic matrices (i.e., HDPE, RHDPE, and VHDPE/RHDPE), neat RHDPE had the smallest LCTE value, RHDPE based composites did not impose an efficient effect on preventing the thermal expansion caused by heating and cooling cycles. It is because MAPE could not effectively enhance PB dust bonding to RHDPE matrix, so the interface adhesion between $\mathrm{PB}$ dust and matrix was very weak, which made the net effect hardly worked out $[27,28]$. Thus, the declined LCTE of RHDPE based composite mainly contributed to the low LCTE of PB dust. Though it was reported that the introducing of coupling agent can improve thermal expansion of natural fiber filled composite, so much impurity in matrix may resist the covalently link with the PB dust [29-31]. This argument is further supported through previous tensile and impact properties, which suggested the weak interface adhesion between PB dust and RHDPE.

At the $40 \mathrm{wt} \% \mathrm{~PB}$ dust loading level, the LCTE values for HDPE system were, respectively, $90.1 \times 10^{-6} /{ }^{\circ} \mathrm{C}, 88.57$ $\times 10^{-6} /{ }^{\circ} \mathrm{C}$, and $84.41 \times 10^{-6} /{ }^{\circ} \mathrm{C}$ from the cooling and heating cycles. These values are still higher than the reported LCTE values of WPC filled with natural fiber and other fillers. It is probably because during the manufacture of particleboard, wheat straw suffered from high temperature and high pressure, which may reduce the thermal and mechanical properties of WS fiber. On the other hand, the methylene diphenyl isocyanate (MDI) remaining on $\mathrm{PB}$ dust surface may resist MAPE to improve the thermal expansion behaviors of filled composites through enhancing surface adhesion.
3.4. Crystallization and Melting Behavior from DSC. Thermogravimetric analysis was performed to evaluate the behavior of the materials when subjected to the heating such as during thermomechanical processing. The cooling and second heating thermogramic curves of $\mathrm{PB}$ dust/HDPE, PB dust/RHDPE, and PB dust/HDPE/RHDPE blends from DSC measurement are shown in Figure 3, and DSC results of three various types of matrix and composites are summarized in Table 2. $T_{c}$ and $T_{m}$ are peak temperatures of crystallization and melting, respectively. Peak heat flow of cooling run (Hp) presented peak crystallization rate of polymer. The crystallinity level, $X_{c}$, was evaluated from the following equation:

$$
X_{c}=\frac{\Delta H_{\exp }}{\Delta H} \times \frac{1}{W_{f}} \times 100 \%,
$$

where $\Delta H_{\text {exp }}$ is the experimental heat of crystallization, $\Delta H$ is the assumed heat of crystallization of fully crystalline HDPE $(290 \mathrm{~J} / \mathrm{g})$, and $W_{f}$ is the weight fraction of HDPE in the blends $[32,33]$.

As shown in Figure 3, compared with neat HDPE, HDPE, and HDPE/RHDPE, PB dust filled composites had lower melting peak temperatures, higher crystallization peak temperatures, much lower crystallization rates at crystallization peak temperatures, and wider crystalline temperature range, which implies an improvement on the processing temperature of composite.

PB dust content influenced crystallization degree of HDPE, RHDPE, and HDPE/RHDPE dramatically (Table 2). Crystallization degree results calculated from second heating run were fairly close to that from cooling run. The sample $X_{c}$ decreased with the increased WSPB dust loading level. 
TABLE 2: DSC result of VHDPE/fiber, RHDPE/fiber, and VHDPE/RHDPE/fiber composite.

\begin{tabular}{|c|c|c|c|c|c|c|}
\hline \multirow{2}{*}{ System } & \multirow{2}{*}{ Fiber loading (\%) } & \multicolumn{3}{|c|}{ Cooling } & \multicolumn{2}{|c|}{ 2nd heating } \\
\hline & & $T_{c}$ & $\mathrm{Hp}$ & $X_{c}$ & $T_{m}$ & $X_{c}$ \\
\hline \multirow{3}{*}{ VHDPE } & 0 & 121.2 & 5.7 & 84.8 & 134.3 & 89.3 \\
\hline & 20 & 121.8 & 5.2 & 79.4 & 134.0 & 84.7 \\
\hline & 40 & 121.7 & 4.1 & 72.5 & 133.6 & 78.8 \\
\hline \multirow{3}{*}{ RHDPE } & 0 & 117.7 & 4.4 & 54.7 & 128.8 & 57.4 \\
\hline & 20 & 118.1 & 3.7 & 52.0 & 128.4 & 55.3 \\
\hline & 40 & 117.2 & 2.8 & 45.7 & 128.0 & 51.3 \\
\hline \multirow{3}{*}{ VHDPE/RHDPE } & 0 & 120.4 & 5.0 & 68.4 & 132.0 & 72.9 \\
\hline & 20 & 120.4 & 4.3 & 65.4 & 131.8 & 70.8 \\
\hline & 40 & 120.3 & 3.8 & 64.1 & 131.2 & 69.7 \\
\hline
\end{tabular}

$\mathrm{a}, \mathrm{b}, \mathrm{c}$, and $\mathrm{d}$ represent data statistics ranking in Duncan's multiple range tests.

When $40 \mathrm{wt} \%$ PB dust was added, the $X_{c}$ of the composites based on three matrixes decreased to $72.5 \%, 45.7 \%$, and $64.1 \%$, respectively. It was because, by addition of natural fiber, the diffusion rate of HDPE chain was certainly reduced because matrix viscosity at the crystallizing temperature was increased $[34,35]$. This phenomenon was more obviously found in composites based on RHDPE system due to their poor flow ability.

At the $40 \mathrm{wt} \%$ PB dust level, the crystallization degree for all HDPE systems was lower than that of WPC filled with wood fiber at the same loading level. It is probably because the consistence of PB dust was very complex, which contained low fibrous and miscellaneous awn and auricle fibers, with remaining MDI on WS surface. It was reported that so much impurity in matrix might hardly act as nucleation seeds and may greatly resist the crystal growth of polymer [36]. It was believed that the reduction of chain mobility of HDPE overwhelmed that of the nucleation resulting in the lowered crystallization degree. Similar results were reported by Lei et al. $[35,37]$.

As implied from the test results reported in Table 2, Hp showed a moderate decrease with $20 \mathrm{wt} \%$ loading and, then, decrease with further increase of PB dust content at $40 \mathrm{wt} \%$, which are $28.1 \%, 35.3 \%$, and $23.8 \%$ for HDPE, RHDPE, and HDPE/RHDPE systems, respectively. It indicated that the introduction of $\mathrm{PB}$ dust lowered the crystallization rate, and aggregation of $\mathrm{PB}$ dust at higher loading rate resisted the chain mobility of HDPE. As a result, the $T_{c}$ shifted to a lower temperature, and the crystallization rate was obviously lowered.

3.5. Mechanical Properties of Composites with Combined Fillers. The results of Table 3 showed that the combined fillers affected the mechanical properties of composites. Here, both virgin HDPE and recycled HDPE were used to generate a mixed blend (50/50 wt\%) as the matrix. The incorporation of BFs greatly improved mechanical properties. Flexural properties of PB dust/BF/VHDPE/RHDPE composites exhibited an increasing trend as $\mathrm{BF}$ portion of the $\mathrm{PB}$ dust/BF fillers (i.e., $2: 1,1: 1$, and $1: 2$ ) increased. Compared to the VHDPE/RHDPE, the flexural strength and modulus of $\mathrm{PB}$ dust/BF/VHDPE/RHDPE composites increased by $150 \%$ and $247 \%$, respectively, when $\mathrm{PB}$ dust/BF ratios reached $1: 2$, which exhibited the high strength and well-dispersed BFs play an important role in determining the flexural properties. Tensile strength and modulus of $\mathrm{PB}$ dust/BF/VHDPE/RHDPE composites increased by $46 \%$ and $255 \%$ when $\mathrm{PB}$ dust/BF ratio was 1:1. A slight decrease of tensile properties with the increasing BF content was observed. The decreasing trend could be associated with the insufficient interfacial adhesion between two fillers with different slenderness ratio.

Table 3 also shows test data of the notched Izod impact strength of $\mathrm{PB}$ dust/BF/VHDPE/RHDPE composites, which exhibited a significant decrease compared to that of VHDPE/RHDPE matrix. The stiffness of the hybrid composites increased with the addition of combined filler and possible strength concentration caused by fiber aggregation, thus resulting in the reduced toughness of the composites. On the other hand, the hydrophilic nature of the PB dust and $\mathrm{BF}$ and the contrasting hydrophobic nature of HDPE matrix exacerbate the agglomeration problem, thus resulting in the decrease of impact properties. Similar behavior for wheat straw fiber and inorganic filler reinforced PP composites was observed in the previous study [22].

3.6. Thermal Expansion Properties of Composites with Combined Fillers. The measured LCTE values of $\mathrm{PB}$ dust/BF/ VHDPE/RHDPE composites over three temperature ranges (i.e., 20 to $60^{\circ} \mathrm{C}, 60$ to $-30^{\circ} \mathrm{C}$, and -30 to $20^{\circ} \mathrm{C}$ ) are listed in Table 4 at three $\mathrm{PB}$ dust/BF ratios. As the BF portion of the PB dust/BF fillers increased, the LCTE values decreased markedly, which was suggested to be able to achieve a desirable dimensional stability for composites. The LCTE value of $\mathrm{PB}$ dust/BF/VHDPE/RHDPE composites at $\mathrm{PB}$ dust/BF ratios of $2: 1,1: 1$, and $1: 2$ were, respectively, $56.6 \times$ $10^{-6} /{ }^{\circ} \mathrm{C}, 50.2 \times 10^{-6} /{ }^{\circ} \mathrm{C}$, and $44.1 \times 10^{-6} /{ }^{\circ} \mathrm{C}$. These values are much lower than that of individual PB dust filler composites. Possible reasons for the decreasing trend of LCTE include the lower LCTE of BF than that of PB dust, which was able to pose a mechanical restraint on the opening of the polymer chain during the heat and cooling cycles and helped decrease the overall LCTE of composites [38]. 


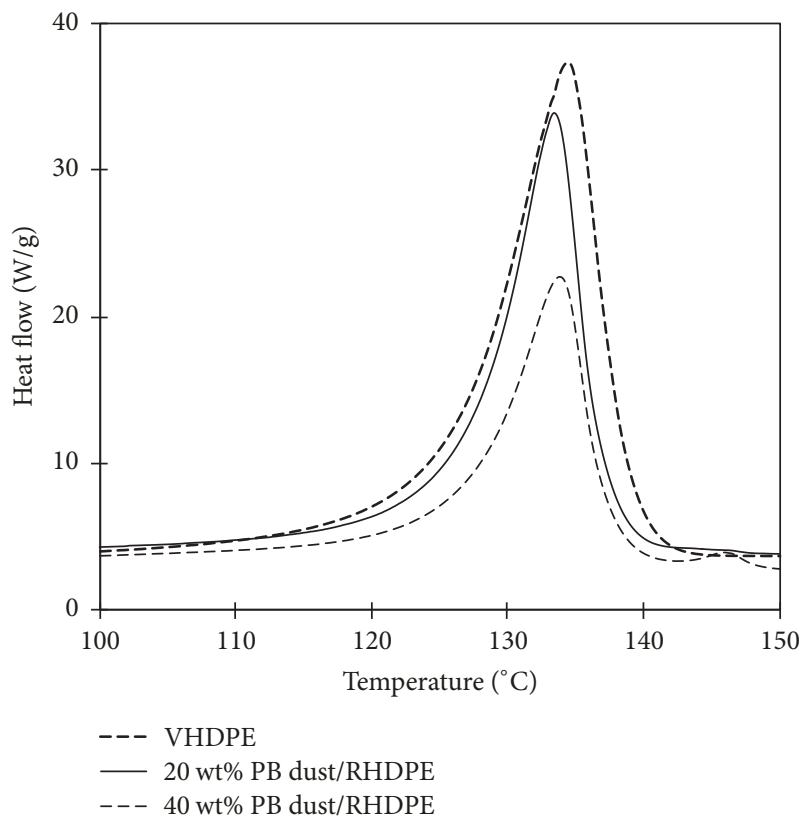

(a)

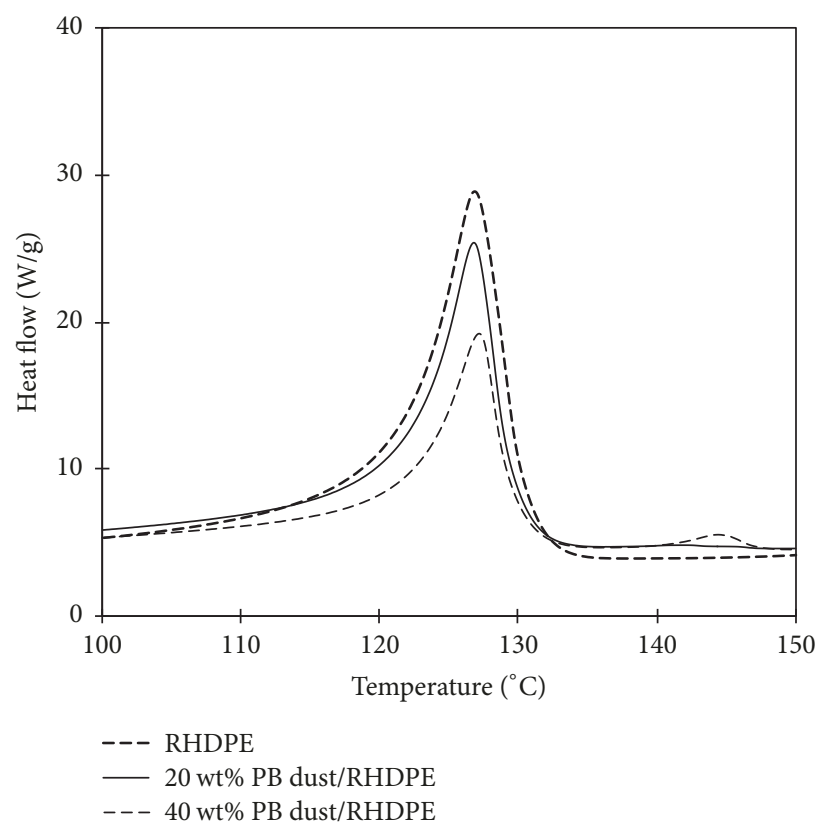

(b)

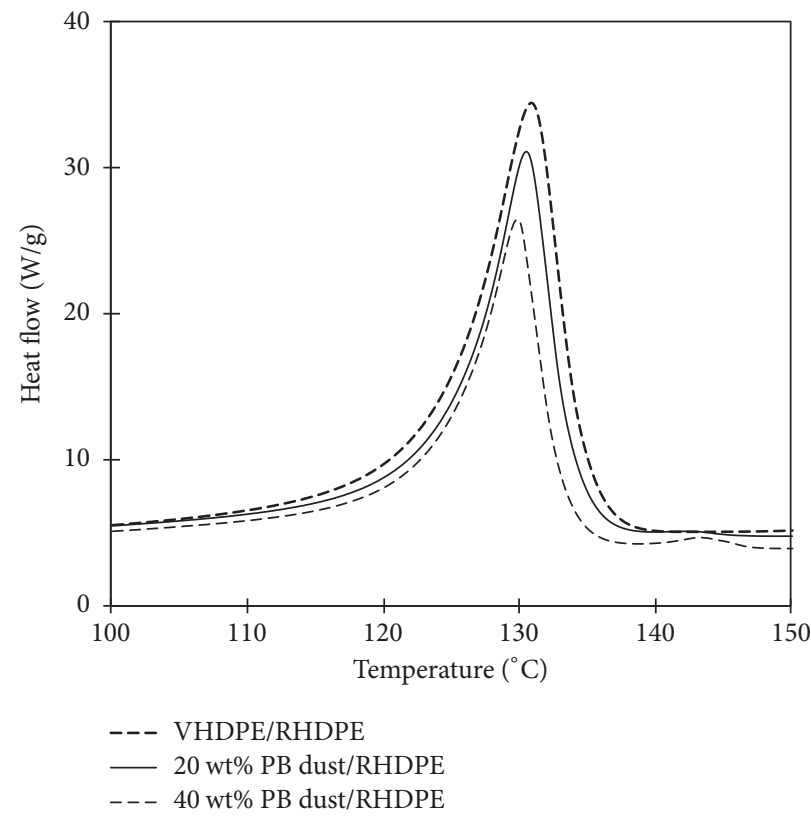

(c)

Figure 3: DSC curves of (a) PB dust/HDPE, (b) PB dust/RHDPE, and (c) PB dust/HDPE/RHDPE.

\section{Conclusions}

The effect of individual and combined PB dust and basalt fibers on mechanical and thermal performance of the filled VHDPE and RHDPE composites was studied. Application of PB dust could be a possible solution for the problem due to the potential low cost of this fiber as well as good mechanical performance. The following conclusions could be drawn from the results of the present study:

(1) The use of PB dust had a positive effect on improving mechanical properties and on reducing LCTE values of filled composites, because the adhesive of the particle board held the wheat straw fibers into bundles, which made PB dust have a certain aspect ratio and high strength.

(2) At the $40 \mathrm{wt} \% \mathrm{~PB}$ dust level, the crystallization degree for all HDPE systems was lower than that of WPC filled with wood fiber at the same loading level, which it was believed that the reduction of chain mobility of HDPE overwhelmed that of the nucleation resulting in the lowered crystallization degree.

(3) As the BF portion of the PB dust/BF fillers increased, the LCTE values decreased markedly, which was suggested 
TABLE 3: Mechanical properties of HDPE and filled HDPE composites with combined fillers.

\begin{tabular}{|c|c|c|c|c|c|c|c|}
\hline \multirow[b]{2}{*}{ System } & \multirow[b]{2}{*}{ Filler content (wt\%) } & \multirow[b]{2}{*}{$\mathrm{PB}$ dust/BF ratio } & \multicolumn{3}{|c|}{ Strength } & \multicolumn{2}{|c|}{ Modulus } \\
\hline & & & $\begin{array}{l}\text { Tensile } \\
\text { (MPa) }\end{array}$ & $\begin{array}{c}\text { Flexural } \\
(\mathrm{MPa})\end{array}$ & $\begin{array}{l}\text { Impact } \\
\left(\mathrm{KJ} / \mathrm{m}^{2}\right)\end{array}$ & $\begin{array}{l}\text { Tensile } \\
\text { (GPa) }\end{array}$ & $\begin{array}{c}\text { Flexural } \\
(\mathrm{GPa})\end{array}$ \\
\hline VHDPE/RHDPE & 0 & 0 & $19.4(0.2)^{\mathrm{a}}$ & $19.1(0.5)^{\mathrm{a}}$ & $9.6(0.2)^{\mathrm{d}}$ & $0.96(0.05)^{\mathrm{a}}$ & $0.73(0.02)^{\mathrm{a}}$ \\
\hline VHDPE/ & & $2: 1$ & $24.1(1.3)^{b}$ & $45.2(0.9)^{c}$ & $6.3(0.3)^{b}$ & $4.03(0.16)^{d}$ & $2.15(0.06)^{\mathrm{c}}$ \\
\hline RHDPE/ & 50 & $1: 1$ & $28.3(1.5)^{\mathrm{d}}$ & $40.9(1.3)^{\mathrm{b}}$ & $6.7(0.4)^{\mathrm{c}}$ & $3.4(0.09)^{\mathrm{c}}$ & $2.01(0.09)^{\mathrm{b}}$ \\
\hline $\mathrm{PB}$ dust/BF & & $1: 2$ & $26.2(1.4)^{c}$ & $47.8(1.5)^{\mathrm{d}}$ & $6(0.4)^{\mathrm{a}}$ & $3.15(0.08)^{\mathrm{b}}$ & $2.52(0.07)^{\mathrm{d}}$ \\
\hline
\end{tabular}

a, b, c, and d represent data statistics ranking in Duncan's multiple range tests.

TABLE 4: Thermal expansion properties of HDPE and filled HDPE composites with combined fillers.

\begin{tabular}{|c|c|c|c|c|c|}
\hline \multirow{2}{*}{ System } & \multirow{2}{*}{ Filler content (wt\%) } & \multirow{2}{*}{$\mathrm{PB}$ dust/BF ratio } & \multicolumn{3}{|c|}{$\operatorname{LCTE}\left(10^{-6} /{ }^{\circ} \mathrm{C}\right)$} \\
\hline & & & $20 \rightarrow 60^{\circ} \mathrm{C}$ & $60 \rightarrow-30^{\circ} \mathrm{C}$ & $-30 \rightarrow 20^{\circ} \mathrm{C}$ \\
\hline VHDPE/RHDPE & 0 & 0 & $155.7(4.5)^{\mathrm{d}}$ & $154.7(7.3)^{\mathrm{d}}$ & $129.5(1.8)^{\mathrm{d}}$ \\
\hline VHDPE/ & & $2: 1$ & $118.1(2.1)^{c}$ & $107.8(5.5)^{\mathrm{c}}$ & $97.2(3.4)^{\mathrm{c}}$ \\
\hline RHDPE/ & 50 & $1: 1$ & $77.3(2.6)^{\mathrm{b}}$ & $68.7(1.1)^{\mathrm{b}}$ & $60.7(1)^{\mathrm{b}}$ \\
\hline $\mathrm{PB}$ dust/BF & & $1: 2$ & $56.6(1.0)^{\mathrm{a}}$ & $50.2(0.8)^{\mathrm{a}}$ & $44.1(2.6)^{\mathrm{a}}$ \\
\hline
\end{tabular}

$\mathrm{a}, \mathrm{b}, \mathrm{c}$, and d represent data statistics ranking in Duncan's multiple range tests.

to be able to achieve a desirable dimensional stability for composites.

(4) The MDI remaining on PB dust surface could lead to the weak interface adhesion between combined fillers and matrix, resulting in a weak composite when $\mathrm{PB}$ dust is at a larger portion.

\section{Conflicts of Interest}

The authors declare that there are no conflicts of interest regarding the publication of this paper.

\section{Authors' Contributions}

Haiyan Mao and Min Yu contributed equally to this work.

\section{Acknowledgments}

The authors would like to acknowledge the financial support from the Shaanxi Provincial Department of Education Special Research Project (17JK0092); Doctoral Scientific Research Foundation of Shanxi University of Science \& Technology (Grant BJ16-01); China Postdoctoral Science Foundation: Special Program (2017T100313); China Postdoctoral Science Foundation: General Program (2016M601821 and 2017M623096); Postdoctoral Science Foundation of Jiangsu Province: A Program (1601027A); the National Natural Science Foundation (31500483); and China Scholarship Council: Postdoctoral Program (201508320022).

\section{References}

[1] G. Fu, J. Guo, W. Zhang, P. A. Summers, and P. Hall, "From waste plastics to industrial raw materials: A life cycle assessment of mechanical plastic recycling practice based on a real-world case study," Science of the Total Environment, vol. 601, pp. 1192-1207, 2017.

[2] H. Kallakas, T. Poltimäe, T.-M. Süld, J. Kers, and A. Krumme, "The influence of accelerated weathering on the mechanical and physical properties of wood-plastic composites," Proceedings of the Estonian Academy of Sciences, vol. 64, no. 1S, pp. 94-104, 2015.

[3] C. Homkhiew, T. Ratanawilai, and W. Thongruang, "Composites from recycled polypropylene and rubberwood flour: Effects of composition on mechanical properties," Journal of Thermoplastic Composite Materials, vol. 28, no. 2, pp. 179-194, 2015.

[4] D. Friedrich and A. Luible, "Investigations on ageing of woodplastic composites for outdoor applications: A meta-analysis using empiric data derived from diverse weathering trials," Construction and Building Materials, vol. 124, pp. 1142-1152, 2016.

[5] S. He, L. Zhou, and H. He, "Preparation and properties of wood plastic composites based on tea residue," Polymer Composites, vol. 36, no. 12, pp. 2265-2274, 2016.

[6] Taneli. V. et al., "Softwood Distillate as a Bio-Based Additive in Wood-Plastic Composites, Journal of Wood Chemistry \& Technology, vol. 36, no. 4, p. 10, 2016.

[7] O. Das, A. K. Sarmah, and D. Bhattacharyya, "A sustainable and resilient approach through biochar addition in wood polymer composites," Science of the Total Environment, vol. 512-513, pp. 326-336, 2015.

[8] H. Wu, X. Liang, L. Huang, Y. Xie, S. Tan, and X. Cai, “The utilization of cotton stalk bark to reinforce the mechanical and thermal properties of bio-flour plastic composites," Construction and Building Materials, vol. 118, pp. 337-343, 2016.

[9] S. T. Cholake, R. Rajarao, P. Henderson, R. R. Rajagopal, and V. Sahajwalla, "Composite panels obtained from automotive waste plastics and agricultural macadamia shell waste," Journal of Cleaner Production, vol. 151, pp. 163-171, 2017.

[10] T. Kogo, Y. Yoshida, K. Koganei et al., "Production of rice straw hydrolysis enzymes by the fungi Trichoderma reesei 
and Humicola insolens using rice straw as a carbon source," Bioresource Technology, vol. 233, pp. 67-73, 2017.

[11] W. Li, J. Van den Bulcke, T. De Schryver, and J. Van Acker, "Investigating water transport in MDF and OSB using a gantrybased X-ray CT scanning system," Wood and Science Technology, vol. 50, no. 6, pp. 1197-1211, 2016.

[12] M. Verheyen, W. Beckers, E. Claesen, G. Moonen, and E. Demeester, "Vision-based sorting of medium density fibreboard and grade A wood waste," in Proceedings of the 21st IEEE International Conference on Emerging Technologies and Factory Automation, ETFA 2016, Germany, September 2016.

[13] M. Madhoushi and A. B. Shahrebabak, "Mechanical and Physical Properties of Green Biocomposite Based on Medium Density Fiberboard Sanding Powder/Polyethylene/Nanoclay," Journal of Polymers and the Environment, vol. 25, no. 2, pp. 221228, 2016.

[14] M. Szakacs, "Post industrial wooden raw material as natural fiber base for wood plastic composites based on PVC and," Processing Technologies for the Forest and Biobased Products Industries, p. pp, 2010.

[15] M. Shams, R. Vaysi, and S. Hossinzaheh, "Study on some mechanical properties of composites made from the flour of MDF flour/reed flour and recycled polypropylene," in Proceedings of International Convention of Societyof Wood Science and Technology, Geneva, 2010.

[16] A. Chavooshi and M. Madhoushi, "Mechanical and physical properties of aluminum powder/MDF dust/polypropylene composites," Construction and Building Materials, vol. 44, pp. 214-220, 2013.

[17] M. Chaharmahali, M. Tajvidi, and S. K. Najafi, "Mechanical properties of wood plastic composite panels made from waste fiberboard and particleboard," Polymer Composites, vol. 29, no. 6, pp. 606-610, 2008.

[18] P. Parker, "A summary report on building materials produced from wheat straw," Wood and Fiber Composite Materials, vol. 5, pp. 47-48, 1997.

[19] D. Dziurka, R. Mirski, D. Dukarska, and A. Derkowski, "Possibility of using the expanded polystyrene and rape straw to the manufacture of lightweight particleboards," Maderas: Ciencia y Tecnologia, vol. 17, no. 3, pp. 647-656, 2015.

[20] M. Valente, F. Sarasini, F. Marra, J. Tirillò, and G. Pulci, "Hybrid recycled glass fiber/wood flour thermoplastic composites: Manufacturing and mechanical characterization," Composites Part A: Applied Science and Manufacturing, vol. 42, no. 6, pp. 649657, 2011.

[21] R. Huang, X. Xu, S. Lee, Y. Zhang, B. J. Kim, and Q. Wu, "High Density Polyethylene Composites Reinforced with Hybrid Inorganic Fillers: Morphology, Mechanical and Thermal Expansion Performance," Materials, vol. 6, no. 9, p. 4122, 2013.

[22] M. Yu, R. Huang, C. He, Q. Wu, and X. Zhao, "Hybrid Composites from Wheat Straw, Inorganic Filler, and Recycled Polypropylene: Morphology and Mechanical and Thermal Expansion Performance," vol. 4, p. 12, 2016.

[23] V. Dhand, G. Mittal, K. Y. Rhee, S. Park, and D. Hui, "A short review on basalt fiber reinforced polymer composites," Composites Part B: Engineering, vol. 73, pp. 166-180, 2015.

[24] R. Huang, C. Mei, X. Xu, T. Kärki, S. Lee, and Q. Wu, "Effect of hybrid Talc-basalt fillers in the shell layer on thermal and mechanical performance of co-extruded wood plastic composites," Materials, vol. 8, no. 12, pp. 8510-8523, 2015.
[25] R. Huang, Y. Zhang, X. Xu, D. Zhou, and Q. Wu, "Effect of hybrid mineral and bamboo fillers on thermal expansion behavior of bamboo fiber and recycled polypropylene-polyethylene composites," Bioresources, vol. 7, no. 4, pp. 4563-4574, 2012.

[26] R. Huang, W. Xiong, X. Xu, and Q. Wu, “Thermal expansion behavior of co-extruded wood-plastic composites with glassfiber reinforced shells," Bioresources, vol. 7, no. 4, pp. 5514-5526, 2012.

[27] R. Huang, B.-J. Kim, S. Lee, Z. Yang, and Q. Wu, "Co-extruded wood-plastic composites with talc-filled shells: morphology, mechanical, and thermal expansion performance," Bioresources, vol. 8, no. 2, pp. 2283-2299, 2013.

[28] A. Tezvergil, L. V. J. Lassila, and P. K. Vallittu, "The effect of fiber orientation on the thermal expansion coefficients of fiberreinforced composites," Dental Materials, vol. 19, no. 6, pp. 471477, 2003.

[29] A. Agbossou and J. Pastor, "Thermal stresses and thermal expansion coefficients of n-layered fiber-reinforced composites," Composites Science and Technology, vol. 57, no. 2, pp. 249260, 1997.

[30] Z. H. Karadeniz and D. Kumlutas, "A numerical study on the coefficients of thermal expansion of fiber reinforced composite materials," Composite Structures, vol. 78, no. 1, pp. 1-10, 2007.

[31] S. Mohanty, S. K. Verma, and S. K. Nayak, "Dynamic mechanical and thermal properties of MAPE treated jute/HDPE composites," Composites Science and Technology, vol. 66, no. 3-4, pp. 538-547, 2006.

[32] A. Choudhury, "Isothermal crystallization and mechanical behavior of ionomer treated sisal/HDPE composites," Materials Science and Engineering: A Structural Materials: Properties, Microstructure and Processing, vol. 491, no. 1-2, pp. 492-500, 2008.

[33] Mendes, L. Claudio, and S. P. Cestari, "Printability of HDPE/Natural Fiber Composites with High Content of Cellulosic Industrial Waste," Materials Sciences \& Applications, vol. 2, no. 9, pp. 1331-1339, 2011.

[34] Y. Lei, Q. Wu, F. Yao, and Y. Xu, "Preparation and properties of recycled HDPE/natural fiber composites," Composites Part A: Applied Science and Manufacturing, vol. 38, no. 7, pp. 1664-1674, 2007.

[35] Y. Lei, Q. Wu, C. M. Clemons, F. Yao, and Y. Xu, "Influence of nanoclay on properties of HDPE/wood composites," Journal of Applied Polymer Science, vol. 106, no. 6, pp. 3958-3966, 2007.

[36] H. Liu, Q. Wu, and Q. Zhang, "Preparation and properties of banana fiber-reinforced composites based on high density polyethylene (HDPE)/Nylon-6 blends," Bioresource Technology, vol. 100, no. 23, pp. 6088-6097, 2009.

[37] F. Yao, Q. Wu, Y. Lei, and Y. Xu, "Rice straw fiber-reinforced high-density polyethylene composite: Effect of fiber type and loading," Industrial Crops and Products, vol. 28, no. 1, pp. 63-72, 2008.

[38] Q. Wu, K. Chi, Y. Wu, and S. Lee, "Mechanical, thermal expansion, and flammability properties of co-extruded wood polymer composites with basalt fiber reinforced shells," Materials and Corrosion, vol. 60, pp. 334-342, 2014. 


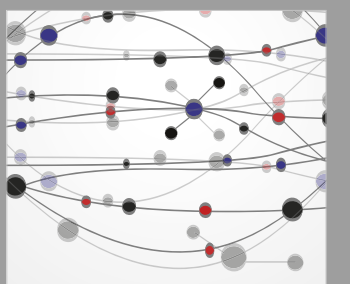

The Scientific World Journal
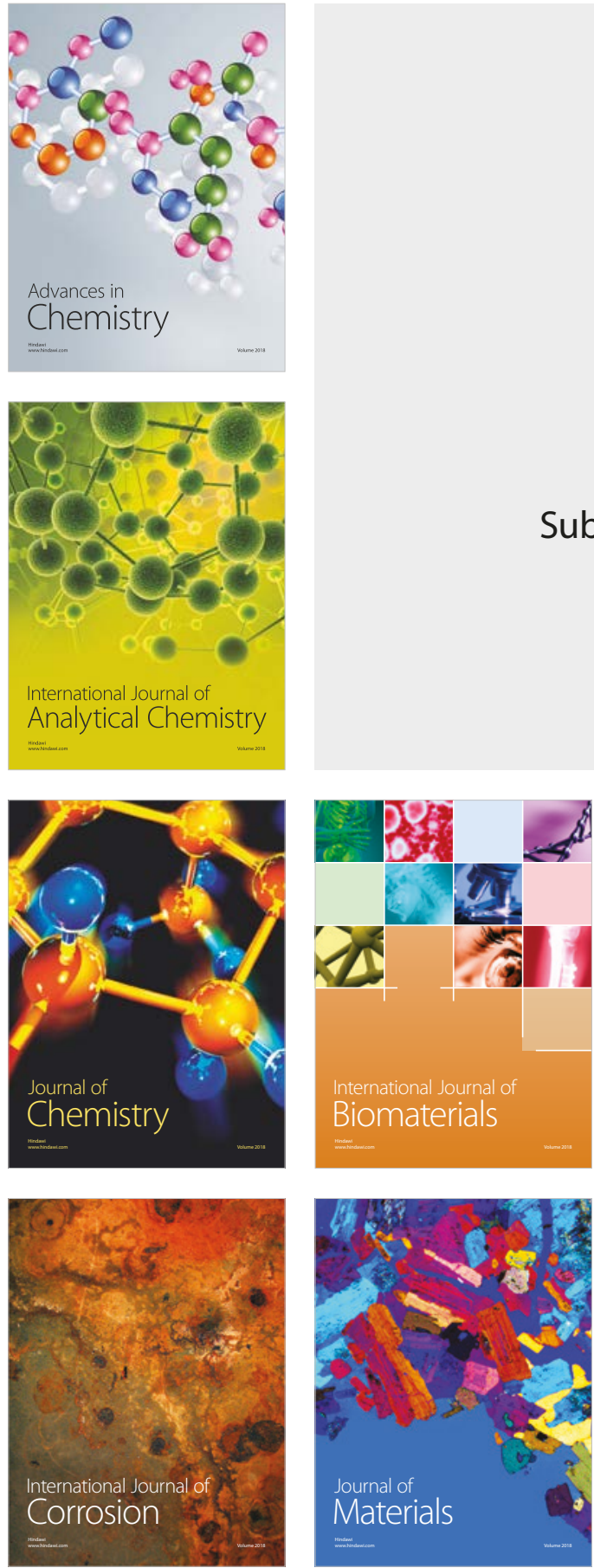

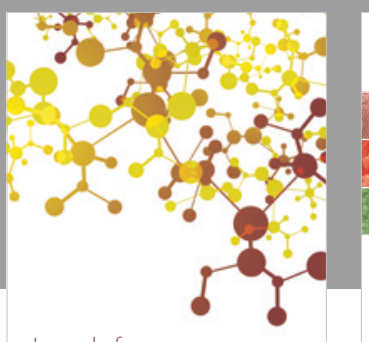

Journal of

Applied Chemistry
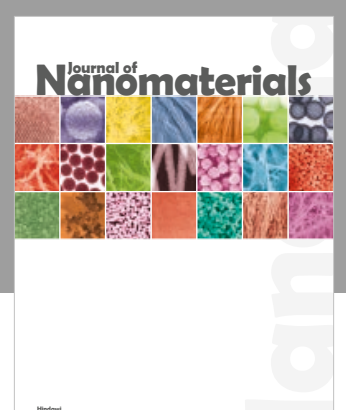

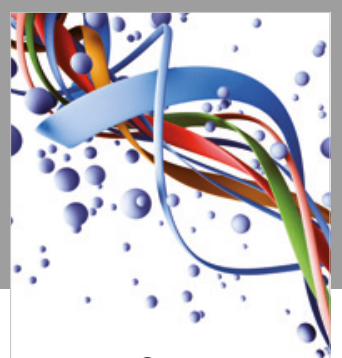

Scientifica

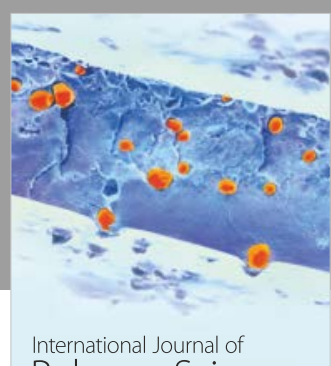

Polymer Science

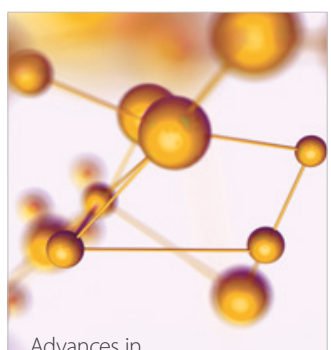

Physical Chemistry
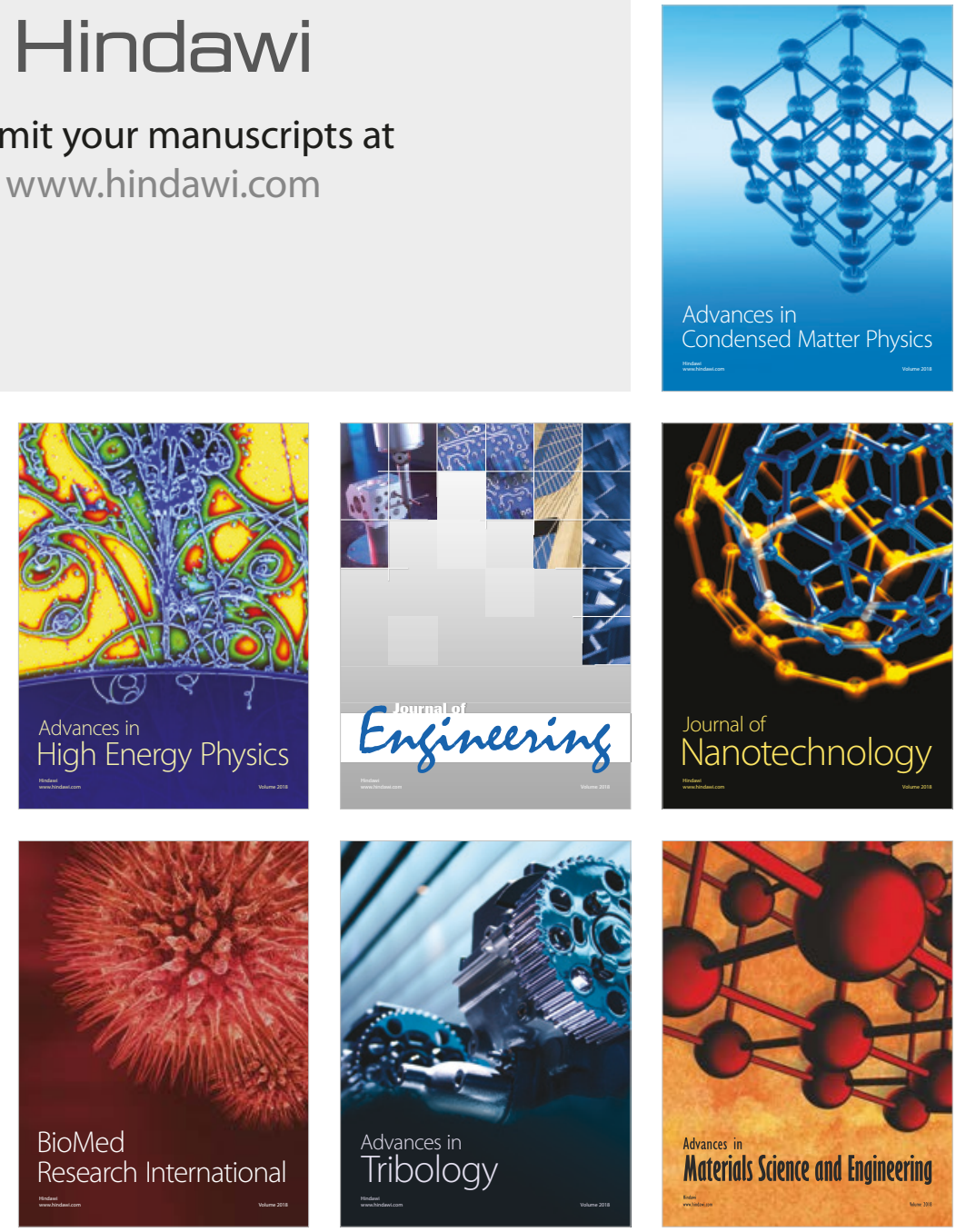